\title{
A study of hyperbilirubinaemia in clinical practice
}

\author{
R. J. AвBOtT \\ M.R.C.P.* \\ M. D. CLEE \\ M.R.C.P.* \\ N. W. CARTER \\ IAN A. D. BOUCHIER \\ M.D., F.R.C.P.* \\ * Department of Medicine, and \\ †Computer Unit. Ninewells Hospital and Medical School, Dundee DD1 9SY
}

\begin{abstract}
Summary
The case records of all patients with an elevated serum bilirubin seen in a hospital group over a consecutive 3-month period were analysed. A judgement was made as to whether the hyperbilirubinaemia had been adequately explained and the aetiology was recorded. Appropriate investigations performed and associated liver function tests were noted.

Eleven per cent. of all bilirubins were elevated. Of 415 patients studied no explanation for the hyperbilirubinaemia was given in $106(26 \%)$. In 287 patients the hyperbilirubinaemia was explained, but in $165(57 \%)$ it was not primarily related to liver or biliary disease. The bilirubin was usually higher and associated liver function tests were more likely to be abnormal when primary hepatobiliary pathology was present. An explanation was more likely to be available when the bilirubin was high $(>24 \mu \mathrm{mol} / \mathrm{l})$ $(1.4 \mathrm{mg} / 100 \mathrm{ml})$. The commonest overall cause of hyperbilirubinaemia was cardiorespiratory failure (30\%).
\end{abstract}

\section{Introduction}

An elevated serum bilirubin is a significant finding which warrants further attention and the differential diagnosis of hyperbilirubinaemia is considerable.

An analysis was undertaken of all adult patients with hyperbilirubinaemia seen in a hospital group in a consecutive 3-month period. The purpose of the study was to examine the incidence of hyperbilirubinaemia and the underlying conditions which are recognized to produce it. The authors studied the manner in which clinicians manage patients with hyperbilirubinaemia and the relation of other standard liver function tests (LFTs) to the elevated bilirubin level.

Using a data base of 11 diagnostic categories,

Reprints and correspondence: Dr R. J. Abbott, Department of Neurology, Dundee Royal Infirmary, Dundee.
Knill Jones et al. (1973) analysed the differential diagnosis of hepatic disease for the purpose of comparison of diagnostic accuracy between clinician and computer. Fraser and Franklin (1974) performed a similar study but expanded the data base to 14 categories. Both studies involved selected populations since all patients suffered with primary hepatic or biliary disease. Manner (1973) looked at the incidence of jaundice in a general practice over a 5 -year period and from a total of over 5000 patients found 42 cases of jaundice, of which 21 were infective in nature.

The present authors are unaware of such a study involving hyperbilirubinaemia in hospital practice.

\section{Methods}

The Dundee laboratory accepts $17 \mu \mathrm{mol} / \mathrm{l}$ $(1.0 \mathrm{mg} / 100 \mathrm{ml})$ as the upper limit of normal for both sexes and reports stating values higher than this are marked with an asterisk when dispatched from the laboratory.

Serum bilirubin is measured by a standard Diazo technique on a Vickers analyser.

With the aid of the hospital computer services all bilirubin values greater than $17 \mu \mathrm{mol} / 1(1.0 \mathrm{mg} / 100$ $\mathrm{ml}$ ) which passed through the routine biochemistry laboratory were collected prospectively over a 3month period from March to June 1977. The case record of each patient with an elevated bilirubin during this period was obtained where possible and analysed retrospectively. The authors looked specifcally to discover whether an explanation had been offered for the elevated serum bilirubin. A judgement was made on the available evidence as to whether appropriate investigations had been performed to account for the hyperbilirubinaemia. In all patients the first abnormal bilirubin received in the laboratory during the study period was recorded together with the following: 
1 Associated liver function tests (LFTs)

Albumin, aspartate transaminase (AST), $\gamma$ glutamyl transpeptidase $(\gamma-$ GTP), and alkaline phosphatase.

\section{Further investigations relating to the hyperbili- rubinaemia}

Liver biopsy, liver scan, a variety of radiological techniques, autoantibodies and hepatitis associated antigen.

\section{The final diagnosis}

This was taken to be the diagnosis recorded in the case summary at the time of discharge. Diagnoses were divided into 2 categories:

a Primary hepato-biliary disease. Cirrhosis/ hepatocellular failure, hepatitis, hepatic malignancy (primary or secondary) and pancreatico/biliary disease.

b Hyperbilirubinaemia not attributable to primary hepato-biliary disease. Postoperative, toxic state, cardio-respiratory failure, metabolic (e.g. diabetes mellitus), miscellaneous (e.g. constitutional hyperbilirubinaemia, haemolysis, malaria). The results were analysed into 2 groups according to the bilirubin level. Patients with a bilirubin level between 18-24 $\mu \mathrm{mol} / \mathrm{l}(1.0-1.4 \mathrm{mg} / 100 \mathrm{ml})$ were placed in Group 1. These figures were regarded as marginally elevated and not unequivocally abnormal. Group 2 contained patients with a bilirubin $>24$ $\mu \mathrm{mol} / 1(1.4 \mathrm{mg} / 100 \mathrm{ml})$ and therefore definitely abnormal.

Results were analysed by the $\chi^{2}$ test.

\section{Results}

The bilirubin was measured in 4220 patients over the 3-month period; $460(11 \%)$ had a level $>17$ $\mu \mathrm{mol} / \mathrm{l}$. Case notes for 45 patients were unobtainable so that 415 patients were studied in all. The age range of the patients was $15-90$ years. No figures from the paediatric wards were included as the $z$ bilirubin estimations were performed in the micro- $\mathbb{Q}$ analysis laboratory and were not recorded on the $C$. computer.

There was no record of an abnormal bilirubin in the case notes of 22 patients (5\%) (Fig. 1).

An explanation for the hyperbilirubinaemia was present in $287(69 \%)$ patients, but in $106(26 \%)$ no $\vec{\varnothing}$ adequate explanation was found. Of the 287 in the $\propto$ explained group $121(43 \%)$ had primary hepato- $\%$ biliary disease whilst $166(57 \%)$ had hyperbili- $\vec{\circ}$ rubinaemia not primarily attributable to either hepatic or biliary disorders (Table 1). Analysis of $\vec{\omega}$ the explained group indicated that the bilirubin in $\frac{\Omega}{8}$ the primary hepatobiliary class was higher and more likely to be accompanied by abnormal LFTs than in the non-primary hepatobiliary class $(P<0.001)$. of More of the explained category were in Group 2 \% whereas the majority of the unexplained category fell into Group $1(P<0.001)$. This suggests that an explanation was more likely in patients in whom the bilirubin was high ( $>24 \mu \mathrm{mol} / \mathrm{l})$.

A detailed breakdown of final diagnoses in the explained group (Table 2) showed that the com- o monest cause of hyperbilirubinaemia was cardiorespiratory failure -87 patients $(30 \%)$. When thes patients were compared with those with primary hepatobiliary disease the bilirubin concentratiog $\overrightarrow{0}$ was usually lower and was frequently $<24 \mu \mathrm{mol}$. $(1.4 \mathrm{mg} / 100 \mathrm{ml})(P<0.001)$.

No adequate explanation was given in the case records for the raised bilirubin in 106 patients (Table 3). In 25 of them alcoholic liver disease was suspected but the diagnosis was not substantiated by liver biopsy. The authors have regarded such patients as incompletely documented. All these patients gave a history of heavy alcohol consumption and 22 had abnormal associated LFTs, usually elevation of the $\gamma$-GTP. This group was classified separately.

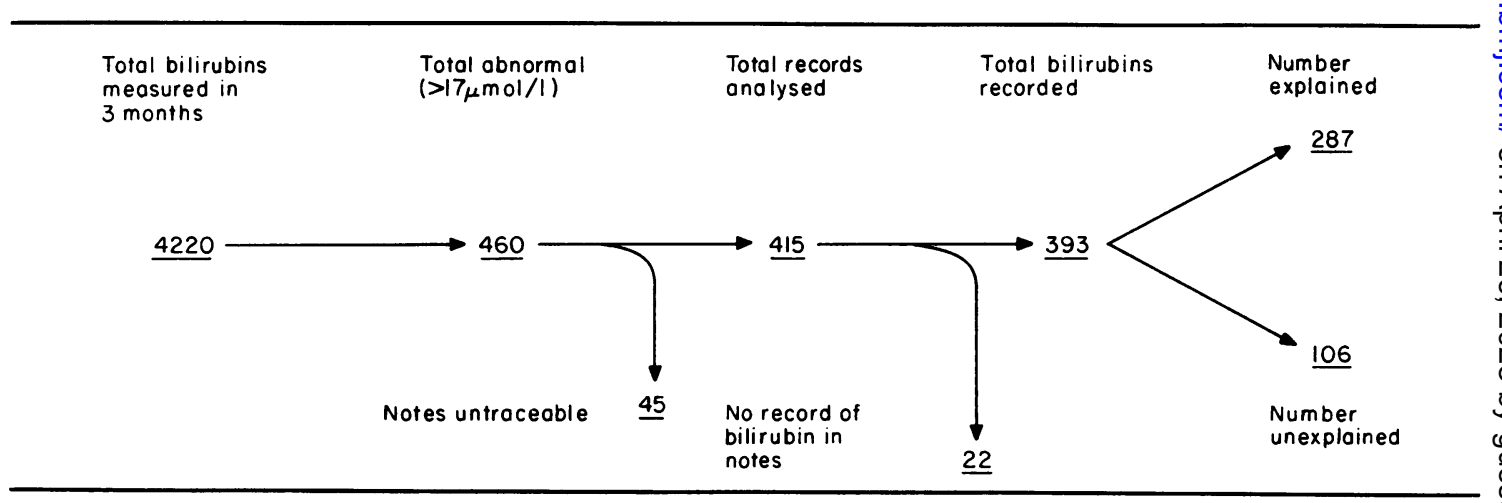

Fig. 1. Flow diagram. 
Of the remaining 81 patients in the unexplained group, the associated LFTs were normal in 69 and abnormal in 12 . In 20 , a repeat bilirubin but no further investigation was performed. It remained elevated in 4 . In 49 patients no repeat test was performed. Only 12 underwent further investigation and in these no explanation of the hyperbilirubinaemia was forthcoming.

The clinical discipline concerned with the management of these patients was identified. Fifty-one had been seen in General Medicine, 19 in General Surgery and 11 in other hospital departments.

\section{Discussion}

This study was performed on an unselected adult population attending a full range of specialist services within a Teaching Hospital Group, and includes both in- and out-patients. For various reasons the hospital records of 45 patients were untraceable but as these were seen in a range of departments the authors believe that failure to trace these notes did not influence the outcome of the study.

TABLE 1. Analysis of 287 explained cases of hyperbilirubinaemia. Patients are grouped into primary and nonprimary hepatobiliary disease. The relation of associated liver function tests to the degree of hyperbilirubinaemia is shown

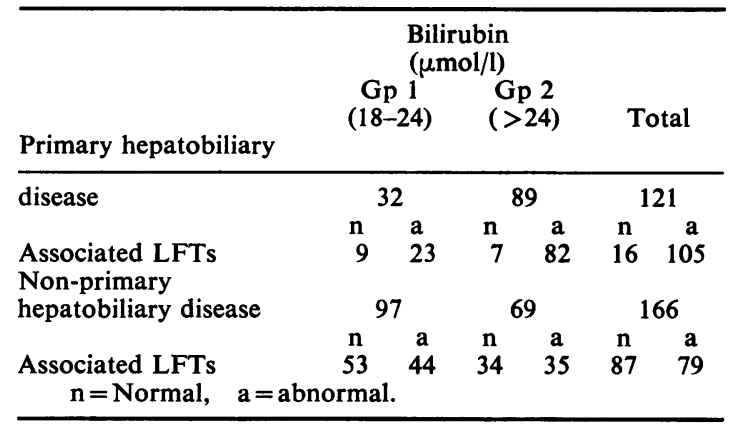

TABLE 2. Detailed analysis of the diagnosis in 287 patients with an explanation for hyperbilirubinaemia

\begin{tabular}{|c|c|c|c|}
\hline & $\begin{array}{r}\text { Bilir } \\
(\mu \mathrm{m} \\
\underset{(18-24)}{1}\end{array}$ & $\begin{array}{l}\text { lbin } \\
\text { l/l) } \\
\text { Gp } 2 \\
(>24)\end{array}$ & Total \\
\hline $\begin{array}{l}\text { Pancreatico-biliary disease } \\
\text { Cirrhosis/hepatocellular failure } \\
\text { Hepatitis } \\
\text { Hepatic malignancy (primary } \\
\text { or secondary) } \\
\text { Post-operative } \\
\text { Toxic } \\
\text { Cardiorespiratory failure } \\
\text { Metabolic } \\
\text { Others (Gilbert's syndrome, } \\
\text { haemolysis, etc.) }\end{array}$ & $\begin{array}{r}17 \\
8 \\
0 \\
7 \\
9 \\
19 \\
58 \\
3\end{array}$ & $\begin{array}{r}41 \\
16 \\
16 \\
\\
16 \\
9 \\
16 \\
29 \\
4\end{array}$ & $\begin{array}{r}58 \\
24 \\
16 \\
\\
23 \\
18 \\
35 \\
87 \\
7\end{array}$ \\
\hline
\end{tabular}

A major problem when studying hyperbilirubinaemia is the difficulty in defining an upper limit of normal for bilirubin. Bailey, Robinson and Dawson (1977) in a large population screen showed a skew distribution and variation according to sex, with an upper limit for males of $25 \mu \mathrm{mol} / 1$ (1.5 $\mathrm{mg} / 100 \mathrm{ml})$ and for females of $19 \mu \mathrm{mol} / \mathrm{l}(1 \cdot 1$ $\mathrm{mg} / 100 \mathrm{ml}$ ). Since reports sent to clinicians from the Dundee laboratory are marked as abnormal when the bilirubin is $>17 \mu \mathrm{mol} / 1(1.0 \mathrm{mg} / 100 \mathrm{ml})$ this value has been taken as the upper limit of normal. Because some clinicians may not accept this figure as defining abnormality, the results have been analysed into a borderline (Group 1) and a definitely abnormal (Group 2) category.

When considering the differential diagnosis of hyperbilirubinaemia most clinicians probably think initially of conditions involving primarily the liver or biliary tract. This study shows that in practice, in the majority of patients, the primary disease process lies elsewhere, since in $57 \%$ of patients where an explanation was found the pathology was not primarily hepatobiliary in origin.

In a review of the literature, Dunn et al. (1973) found the incidence of hyperbilirubinaemia in cardiac failure to be between 27 and $70 \%$. It is usually mild with a bilirubin value not $>5 \mathrm{mg} / 100$ $\mathrm{ml}(86 \mu \mathrm{mol} / \mathrm{l})$ and often $<3 \mathrm{mg} / 100 \mathrm{ml}(52 \mu \mathrm{mol} / \mathrm{l})$ (Felder, Mund and Parker, 1950; Sherlock, 1957; Richman, Delman and Grob, 1961). Hyperbilirubinaemia is commoner in predominantly rightsided failure especially if the onset is acute, and the bilirubin is mainly of the unconjugated variety (Dunn et al., 1973). In a study of 336 patients with unconjugated hyperbilirubinaemia in which overt haemolysis had been excluded congestive cardiac failure was the single commonest aetiological factor (Levine and Klatskin, 1964). The mechanism for the hepatocellular dysfunction is probably anoxia due to a combination of decreased hepatic blood flow and elevated hepatic venous pressure (Dunn et al., 1973). Haemolysis plays a minor role and obstruction

\section{TABLE 3. Analysis of 106 patients with unexplained hyperbilirubinaemia}

\begin{tabular}{|c|c|c|c|}
\hline & $\begin{array}{r}\text { Bil } \\
(\mu \mathrm{m} \\
\underset{G p}{1} \\
(18-24)\end{array}$ & $\begin{array}{l}\text { rubin } \\
\text { l/l) } \\
\text { Gp } 2 \\
(>24)\end{array}$ & Total \\
\hline $\begin{array}{l}\text { Further Investigated } \\
\text { Not Further Investigated }\end{array}$ & 4 & 8 & 12 \\
\hline Alcohol suspected & 16 & 9 & 25 \\
\hline Bilirubin not repeated & 36 & 13 & 49 \\
\hline Bilirubin returned to normal & 11 & 5 & 16 \\
\hline Bilirubin abnormal on repeat & 3 & 1 & 4 \\
\hline Sub total & 66 & 28 & 94 \\
\hline Total & 70 & 36 & 106 \\
\hline
\end{tabular}


to bile canaliculi is unimportant. Cardiorespiratory failure accounted for $30 \%$ of the patients where an explanation for the hyperbilirubinaemia was found; interestingly this figure is similar to Morgan's findings for the incidence of cardiac failure in an unselected population with elevated blood urea (Morgan, Carver and Payne, 1977).

Transient postoperative hyperbilirubinaemia and hyperbilirubinaemia secondary to infection or toxic state together accounted for $53(19 \%)$ patients. The factors responsible for postoperative hyperbilirubinaemia include haemolysis, increased pigment load following transfusion, hepatocellular damage including that attributable to anaesthetics, and extra-hepatic biliary obstruction (Lamont and Isselbacher, 1973). The mechanism of hyperbilirubinaemia secondary to infection remains poorly defined, but the bilirubin is generally in the conjugated form and associated LFTs are less likely to be abnormal than the serum bilirubin concentration (Miller et al., 1976). Studies of such patients have not shown any lesion either at surgery or postmortem (Eley, Hargreaves and Lambert, 1965; Vermillion et al., 1969).

In the 121 patients with primary hepatobiliary disease the commonest mechanism for the hyperbilirubinaemia was pancreatico-biliary pathology $(58 \%)$. Biliary calculi accounted for the majority of these.

In $106(26 \%)$ patients no adequate explanation for the hyperbilirubinaemia was recorded in the notes. Of these, $94(89 \%)$ had no investigation other than the performance of routine LFTs. In 16 patients, the bilirubin had returned to normal when repeated and in 25 , liver dysfunction was attributed to alcohol abuse, although in the authors' opinion on unsatisfactory grounds. The majority of the 94 patients had minimally elevated bilirubin values $(70 \%$ in Group 1) and possibly the clinicians regarded the bilirubin as not sufficiently abnormal to warrant further investigation.

The majority of unexplained patients were under the care of physicians and appear to have been discovered on 'routine' liver function testing. This probably reflects the comparative frequency of routine screening tests on medical wards compared with other departments.

Overall only $11 \%$ of all bilirubins measured were found to be abnormal. Surprisingly, over a quarter of these were unexplained, of which only $12 \mathrm{had}$ investigations other than simple biochemical tests of liver function. Occasionally, abnormal results were $\frac{3}{8}$ disregarded for a good reason, for example when the level had returned rapidly to normal, or when there was a strong suspicion of alcohol abuse, but further investigation was not practicable. However, a large $\overrightarrow{0}$ number of unequivocally abnormal bilirubin results remained unexplained and even uninvestigated.

The advantage of testing liver function routinely $\overparen{D}$ is debatable, but if this policy is pursued some attempt should be made to explain abnormal findings however unexpected they may be.

\section{Acknowledgments}

We thank Mrs Dorothy Kane and Mrs Margot Caird and also the Medical Records departments of the Dundee Hospitals for help in tracing the case records.

\section{References}

Bailey, A., Robinson, D. \& Dawson, A.M. (1977) Does Gilbert's disease exist? Lancet, i, 931.

DUNN, G.D., HAYES, P., BREEN, K.J. \& SCHENKER, S. (1973) The liver in congestive heart failure - A review. American 0 Journal of the Medical Sciences, 265(3), 174.

Eley, A., Hargreaves, T. \& Lambert, H. (1965) Jaundice in severe infections. British Medical Journal, 2, 75.

Felder, L., MUND, A. \& PARKer, J.G. (1950) Liver function tests in chronic congestive heart failure. Circulation, 2, 286.

Fraser, P.M. \& FrankLIN, D.A. (1974) Mathematicifl models for the diagnosis of liver disease. Quarterly Journol of Medicine, 43, 73.

KNILl Jones, R.P., Stern, R.B., GiRmes, D.H., MAXweli, J.D., Thompson, R.P.H. \& Williams, R. (1973) Uses of . sequential Bayesian model in diagnosis of jaundice computer. British Medical Journal, 1, 530.

LAMONT, J.T. \& IsselBaCHER, K.J. (1973) Postoperative jaundice. New England Journal of Medicine, 288, 305.

LEVINE, R.A. \& KLATSKIN, G. (1964) Unconjugated hyperbilirubinemia in the absence of overt hemolysis. $\frac{2}{2}$ American Journal of Medicine, 36, 541.

MANNERS, B.T.B. (1973) The investigation and aetiology of $\overrightarrow{\overrightarrow{0}}$ jaundice in a general practice. Journal of the Royal College 3 of General Practitioners, 23, 357.

Miller, J.D., KeETON, G.R., WebBer, B.L. \& SAunders, S.J.吾 (1976) Jaundice in severe bacterial infection. Gastroenterology, 71(1), 94.

Morgan, D.B., CARver, M.E. \& PAyne, R.B. (1977) Plasma creatinine and urea: creatinine ratio in patients with raised plasma urea. British Medical Journal, 2, 929.

Richman, S.M., Delman, A.J. \& Grob, D. (1961) Alteration in indices of liver function in congestive heart failure with $O$ particular reference to serum enzymes. American Journal

of Medicine, 30, 211.
SHERLOCK, S. (1957) The liver in heart failure. British Heart Journal, 13, 273.

Vermillion, S.E., GregG, J.A., Baggenstoss, A.H. \& BARTHOLOMEW, L.G. (1969) Jaundice associated with N bacteremia. Archives of Internal Medicine, 124, 611. 